\title{
CONSTRUCTING OUR IDENTITIES: IDENTITY EXPRESSION AMONGST LESBIAN WOMEN ATTENDING UNIVERSITY
}

\author{
D. M. Prado-Castro*
}

e-mail: daniela1master@gmail.com

\author{
T. M. Graham* \\ e-mail: Tanya.Graham@wits.ac.za \\ *Department of Psychology \\ University of the Witwatersrand \\ Johannesburg, South Africa
}

\section{ABSTRACT}

Issues of marginalisation have been central to studies on lesbian women, and can affect the expression of sexuality. The university is a site that can potentially provide a physical and relational space that facilitates the negotiation of identities within the context of institutional policies and spaces that protect LGBTI people. This article examines data collected from 3 focus group discussions with 11 lesbian women attending a metropolitan university. Using queer theory, this article explores their identity expression; identification with 'categories' of lesbianism; the intersections of sexual identity with other social markers; and the interplay of space and identity expression. The data were audio-recorded and analysed using thematic content analysis. The results of the study indicated new emerging ways of viewing and expressing lesbian identity. The results show intersections of identity expression with shifts in policies, Westernisation, privilege, and power, as well as an increase in LGBTI consciousness and access to information, has allowed for wider expressions of sexuality that attempt to break gender binaries.

Keywords: intersectionality, lesbian identity, queer theory, sexuality, university

\section{INTRODUCTION}

Identity development and expression is especially challenging for lesbian women who are faced with unique challenges as a minority group. In South Africa, research on alternative sexual identities has been neglected, especially in psychology (Potgieter 2003, 269). Much of the existing research has focused exclusively on homosexuality, including lesbianism, in white middle class populations (Potgieter 2003, 269), or has centred on gay and lesbian people as targets of violence and crime (e.g. Nel and Judge 2008, 20). Much of the focus on lesbian identity has examined the complexities of the 'coming out process' in identity development (e.g. Kotze 2010, 1-77), but there has been less focus on the ongoing development and 
expression of lesbian identity after 'coming out' in the South African context. Identity expression among lesbian women in South Africa is particularly affected by the broader context of violence and prejudice in the country. Hate crimes or violence associated with prejudice further marginalise this group that already suffers the burden of discrimination and oppression (Gontek 2009, 1; Harris 2004, 1). The experience of social prejudice and the fear of violence can impede the expression of lesbian identities in public and private spheres. This article examines the constructions of identity in self-identified lesbian women in the stage of young adulthood, and explores how identity is negotiated in a contemporary metropolitan university environment. The research specifically explores identity expression in women after 'coming out', where women have already engaged in the transition to being open about their sexuality and have self-disclosed their sexual orientation to others (Griffith and Hebl 2002, 1191). This research aims to provide some insight into the negotiation and expression of sexual identities in young adulthood, with an explicit focus on identification with 'categories' of lesbianism, including historical and emerging categories in contemporary South Africa. The study uses queer theory to explore constructions of identity within lesbian women at university. In addition, the concept of intersectionality is used to strengthen the argument that identity development is continuous and non-linear, and that identity is created in conjunction with other social markers (Butler 1999, 1-30; Geers and Van der Tuin 2013, 174).

In order to situate the focus of this study, the article begins with an overview of some of the pertinent literature as background to the study. Firstly, the article considers the 'categories' of lesbianism that have been historically identified in literature on sexual identity. It then considers the contemporary shift towards examining identity in terms of acknowledging identity intersectionalities, in order to gain a more complex understanding of how identities are constructed. The article then examines some of the specific cultural and contextual features that affect lesbian identity construction within South Africa. Lastly, the article outlines the queer theory approach that was used to inform the conceptualisation of the study that follows. The article illustrates that the university setting provides an important space for identity expression for this socially marginalised group, and shows the complexity of the intersectionalities of lesbian identity in ways that challenge existing categories and gender binaries.

\section{BACKGROUND TO THE STUDY}

\section{Categories of lesbianism}

Several 'categories' of lesbian identification have previously been articulated in literature on 
lesbian identity development. However, understanding lesbian identity poses similar problems to understanding homosexuality; that is, that meanings are highly subjective. Butch and femme are two of the most common terms used to categorise lesbianism (Eves 2004, 480; Walker, Golub, Bimbi and Parsons 2012, 104). Their popularity is attributed to these identities being frequently understood to be derivatives of the heterosexual male/female gender performance (Eves 2004, 494; Walker et al. 2012, 91). In these categories, women are expected to adhere to heterosexual norms even in lesbian relationships (Harris 2002, 73).

Some of these terms have been developed by the queer community to build a sense of belonging and a common language (Balteiro 2015, 308; Walker et al. 2012, 90). This discourse has often been referred to as 'pink' (Smorag 2008, 2) or 'lavender' language (Kulick 2000, 247). Other common terms are: Granola lesbians (health conscious lesbians); Soft butches (masculine women who have a soft affectionate side); Sugar daddies (older women who have younger partners); Fish (young lesbians); Lipstick lesbians (fashionable and feminine); Chap stick lesbians (lesbians who don't wear makeup, but are feminine and into sports); Leather dykes \& tomboys (Smorag 2008, 4).

In a study by Stanley (1970, 45-59), one of the first of its kind, she provided her participants with some terms and asked them about their understandings and perceptions; she also gave them the opportunity to include more terms. Stanley $(1970,45-59)$ assumed that an increase in use of this slang by members of the LGBTI community contributed to the construction of a discourse. Stanley has been repeatedly cited over the years, which demonstrates continuity in queer slang, as well as the function this language has served within the lesbian community (see e.g. Balteiro 2015, 307-311; Kulick 2000, 271-272).

Three aspects are commonly mentioned by literature on lesbianism: The consideration of sexual identity as either homosexual or heterosexual (which ignores other possibilities for sexuality); secondly, the behaviour which requires engagement in 'homosexual acts', and finally a choice or self-identification as a homosexual (lesbian) (e.g. Eves 2004, 480-496). The aspect of choice paves the way for questions regarding the categories that lesbians are placed or place themselves into, and the process of choosing to identify with certain categories. This is of particular relevance in the present study, which sought to examine how lesbian women situate their identities in relation to such categories.

\section{Identity development and intersectionality}

The development of a sexual identity is often related to gender identity. This is due to the heteronormative expectations of how males and females are expected to behave (Mooney and Kiguwa 
2009, 601-602). Gender identity serves to normalise the behaviours of men and women in society and serves to exclude the 'other'. In attempting to understand the differences between the participants in this study, it is important to recognise other intersections of identity. Intersectionalities can be described as the interplay of various social constructs (Davis 2008, 67). Thinking in terms of intersectionalities helps transcend focusing on one dimensional identity politics and allows for a web of identity to be formed (Hill Collins 1998). In the identity development of lesbians, other identities, such as gender, race, class, and religion, intersect with sexual identity (Davis 2008, 68-76). This sheds light on the complexities that lesbian women may face when negotiating their identities.

\section{Lesbianism in South Africa}

In order to explore the constructions and expressions of identity among lesbian women, it is necessary to situate this focus within the broader socio-political and cultural context related to sexual orientation in South Africa. There is a strong belief in South Africa that homosexuality is a Western concept and thus it is 'un-African' (Gontek 2009, 4; Berman cited in Potgieter 2003, 270). This belief has a clear impact on cultural practices, as well as the politics that surround LGBTI individuals (Moonsammy 2009, 69; Potgieter 2003). Potgieter (2003) demonstrates how homosexuality has been present in Africa for many centuries and offers the example of 'women marriage among the Luvedu in the Northern Province ... the Venda ... and the Zulu's' (Potgieter 2003, 276-280). Although there are some examples of homosexuality in South Africa and specifically in African cultures, they have not been documented or are not understood as homosexuality. Some life stories have been recently documented which depict the lives of lesbians, specifically in black communities in South Africa, and how they are able to negotiate their sexuality in a culturally unaccepting society (see e.g. Pakade 2013). 'Black bull, ancestors and me: My life as a lesbian Sangoma' (Nkabinde 2008) documents the life of Nkunzi Zandile Nkabinde, a black lesbian Sangoma, and her search for a balance between her traditions and her life as a lesbian.

Cultural beliefs together with Apartheid policies paved the way for the construction of a society which was unaccepting of homosexuality (Moonsammy 2009, 2). More recently reports of violence against lesbians, corrective rape, and 'hate crimes' have taken the forefront in the media (see e.g. Davis 2012, 1). Hate crimes are attacks against the victim and the group to which the person belongs, and are thus seen as 'message crimes' (Harris 2004, 1).

The focus of homosexuality research in South Africa is geared towards understanding and changing hate crime (e.g. Thomas 2013). This stems from an increasing recognition of the need 
to protect the constitutional rights of LGBTI individuals (Gontek 2009). However, this also highlights the lack of research in areas that do not have a focus on violence. Some LGBTI organisations have actively worked on gathering life stories which demonstrate that homosexuality cuts across race, gender, socio-economic status and even disability. This has provided insight into a marginalised group of people and the complexities of their intersecting identities in relation to the unique history and context of South Africa.

\section{A queer theory perspective}

Queer theory encompasses identity construction, especially related to homosexuality and the expression of sexual identity. 'Queer' is not simply a theory but also a word to which meanings are attached and to which identification is possible. According to Jagose $(1996,97)$ 'queer is widely perceived as calling into question conventional understandings of sexual identity by deconstructing the categories, oppositions and equations that sustain them'.

Gender identity is one aspect of identity in which performance plays a crucial role (Butler 1999); and thus gender is linked to queer theory. Judith Butler, one of the most influential theorists of gender and queer theory, proposed that gender is a 'cultural fiction' created through the repetition of acts which become normalised over time. Butler $(1999,190)$ referred to this behaviour as 'performative', even though this is not a chosen but a given performance. Overall, it is apparent that gender constructs have privileged heterosexuality and deconstructing these beliefs legitimates other sexual identities.

Queer theory also applies to the queering of spaces. Queer spaces are those spaces which are not heterosexual spaces. However queer spaces, much like the rest of queer theory, goes beyond the hetero-normative formulations and also beyond gender and sexuality. 'Just as individual persons don’t have pre-existing sexual identities, neither do spaces' (Bell, Binnie and Valentine cited in Oswin 2008, 90). Spaces are important because these are the foundations where queerness is played out. According to Oswin $(2008,100)$, spaces are constructed to reflect constellations of power, and therefore are made to fit particular sexualities. For some, queer spacing is about 'colonising' spaces which were previously exclusively heterosexual. However, Oswin $(2008,1)$ argues that queer spacing should be deconstructed alongside other forms of social exclusion in a broader analysis of intersecting power relations. Through using a queer theory perspective, this study views identity as fluid and performed in a manner that is responsive to the institutional setting, physical environment and relational context in which individuals are located. In the section that follows, we describe the methods that were used in this study to collect data on the identity constructions of lesbian women attending university. 


\section{METHOD}

\section{Research design}

The study utilised a qualitative research design to capture the constructions of identity among young lesbian women in a university context. Qualitative research is concerned with naturalistic inquiry in everyday settings, and involves the analysis of data collected from methods such as participant observation, semi-structured interviews and other documents (Babbie and Mouton 2015, 270).

\section{Participants and sampling method}

Participants were self-identified lesbian women between the ages of 18 and 30, who were registered students at the University of the Witwatersrand at the time of data collection. This was important as it is the university environment that was analysed as a location where identity and meaning creation around identities are taking place. The research made use of purposive sampling, as the researchers approached selected LGBTI groups at the university. However, there was a limitation in relation to self-disclosure and therefore participants were asked to identify other people that they believed could be interested in taking part in the research in a snowball sampling method. It was a necessary criterion that participants had already transitioned through the 'coming out process', in which they had openly expressed their sexual orientation. The purpose of the research was explained to each person and participation was voluntary.

\section{Data collection}

Data were obtained through three focus groups, with three to five self-identified lesbian women in each group. This study adopted a flexible, semi-structured approach of data collection through focus group discussions so as to allow for the participants' experiences to inform the direction of the results (Lewis 2003, 58). The focus groups were between one and two hours in duration and were facilitated by the first author. The focus groups were semi-structured and made use of topics as guides for encouraging conversation as well as yielding focused information on particular areas of interest (Roberts, Sitas and Greenstein 2003, 60). The broad thematic areas were: the historical context, the university space, categories of lesbianism and their personal identities. The focus groups took place in a venue at the university. Voice recording was used to allow for greater accuracy in the reporting of the results and to establish 
better rapport with the participants. All ethical considerations regarding the recording of data were adhered to.

\section{Data analysis}

Through the focus groups the researcher gathered data which answered the research questions. The audio-recorded data were transcribed and analysed in order to yield the links between the content of the interviews and the theoretical framework of the study. The transcripts were analysed using thematic content analysis which required reading the data and identifying the main trends to form themes and subthemes. Thematic content analysis was the preferred method because of its flexibility and applicability to studies within a social constructionist frame (Braun and Clarke 2006, 9). Thematic content analysis is used to interpret aspects within the research by yielding themes and trends within the data (Braun and Clarke 2006, 6). This involved using the six steps outlined by Braun and Clarke (2006, 16-23), namely, 1) engaging in the process of familiarization with and immersion in the data, which is achieved through transcribing, reading and re-reading the data; 2) the generation of initial codes or meaning units within the data; 3) sorting the codes into overarching themes and sub-themes that occur across the data, and structuring these themes; 4) reviewing and refining the themes for clarity, coherence and structure, and developing a thematic chart; 5) naming and defining themes; and lastly 6) writing up the narrative report, using appropriate illustrations of the themes. The data were coded in a theory-driven manner, as the research was concerned with the ways in which constructions of identity articulated with a queer theory approach and with identifying important intersectionalities in the data.

\section{Ethics}

This research adhered to the guidelines stipulated in the Human Research Ethics Committee (Non-medical) of the University of the Witwatersrand. Due to the sensitive nature of the research some specific considerations needed to be acknowledged. All aspects of the research were explained to the participants, in a verbal as well as written manner, using a participant information sheet. All participants signed a consent form that stipulated aspects of participation, as well as a consent form for audio-recording. The identities of the participants were kept confidential. There were limitations to the anonymity of participants due to the use of focus groups. To address this, all participants were individually met by the first author prior to the commencement of research and the limited anonymity was explained. Individuals who agreed to take part in a focus group signed a confidentiality agreement. 


\section{RESULTS}

Through an analysis of the information gathered in the focus group discussions a number of themes, and subthemes were yielded, which are outlined in Table 1.

Table 1: Overview of results

\begin{tabular}{|l|}
\hline Themes and Subthemes in the Analysis \\
\hline 1. Historical and Social Changes \\
2. Categories of Lesbianism \\
$2.1 \quad$ Categories are interpreted in different ways \\
$2.2 \quad$ Categories are limiting boxes \\
3. Importance of Intersectionalities \\
3.1. Age and sexuality \\
3.2. Career and sexuality \\
3.3. Class and sexuality \\
3.4. Culture and sexuality \\
3.5. Race and sexuality \\
4. Social Markers \\
4.1. Homophobia as a social marker \\
4.2. Gender performativity \\
5. Identity and Location
\end{tabular}

\section{Historical and social changes}

The participants were very aware of how the historical and social changes in South Africa affected the expression of sexuality. Most of the participants had not lived their sexuality through the Apartheid period and thus their sense of change was hypothetical. For some participants, there was a sense that the implementation of the Constitution has had negative effects:

I think it's been really detrimental, I think it's been very dangerous and in many ways has caused a lot of harm so whereas before ' 94 there was the potential for an LGBTI movement based on radical politics, based on politics of genuine equality, of racial equality of class unitedness of really fighting oppression that connected LGBTI rights to feminism, etc., has sort of been diluted and lost $(\mathrm{Na})$.

It was a way of security like you said most helpful for the middle class what about the lesbian in the township who doesn't even recognise whether we have rights, how does that protect her. How can she be able to get access to this kind of information in order to protect herself because most of them are being abused or getting killed $(\mathrm{M})$.

The participants perceived the Constitution as both a detrimental tool, as well as an absent tool in aiding equality. They expressed nostalgia at having lost the progress that had been made prior to the Constitution, or the loss of hope of what the Constitution could do for all. The belief that these participants had in the Constitution has further divided the LGBTI movement along class lines. The middle class were able to access the rights that protected them and allowed them day to day freedoms to marry and legally adopt as couples, as well as make use of public spaces. 
However, the black lesbian in the township was still in danger. Black participants were aware of the compounded marginalisation they experienced because of their race, gender, and sexual orientation.

Participants' also expressed positive views of the Constitution with regards to the increasing visibility it provided about LGBTI issues, as well as the recognition of LGBTI people:

I think that it's become more legally acceptable to step forward and say I'm gay, lesbian, bisexual, trans, intersex, or asexual identified. (T).

I think the constitution putting sexual orientation in section 9 plays a huge role in people understanding what does it mean to be homosexual. (Th).

The Constitution increased legal recognition that there were different expressions of sexuality. This provided the opportunity for a level of advocacy and a new kind of visible identity expression to take place.

\section{Categories of lesbianism}

\section{Categories are interpreted in different ways}

Participants were easily able to name categories of lesbianism, some which they had heard from friends, television, or read in books. The categories of 'butch' and 'fem' were most common, and the rest being variations of this. This has also been found in other research (e.g. Eves 2004, 480-496), which is related to the gender binaries that they seem to replicate (Harris 2002, 1). However the interpretation of the labels differed greatly, which sparked debate about their 'real meaning':

Okay the ones that I know under femininity, like extreme fem girls, girly girls, there's the fem, there's a lipstick lesbian, and there's the (I think this is so derogatory) but there's a bottom - which means you are at the receiving end of sexual services. And then there are those in the middle ground, I suppose this is where futch would make an appearance, those in the middle ground would be your androgynous females who are gender neutral who you can't really tell if it's a girl or a boy by looking at, but someone who has strong leaning on both of them for you to be confused or look at them with admiration, and then there are soft studs which is pretty much the same thing, this are just terms that you use. And then my favorite category, the aggressive lesbians, you have butch lesbians, you have aggies which is aggressive - that's for your bordering on trans lesbians who have completely male mannerisms, they have deep voices, they dress like guys 24/7, they bind their chest, they cut their hair, like its yeah dude persona $100 \%$, and then you have studs which is a kind of more sophisticated butch lesbian, because the butch would be like a thug, you know dress with baggie jeans and the typical hiphop persona, a stud would be your ties and suits and whatever. (M).

The idea of a collective identity was present and within this women were able to explore the 
different ways to play out their sexuality. According to Jordanova (1999, 432-444) sexuality has the ability to change; this is clearly evident in how these women are acting out their sexualities. The problems of defining lesbianism were also found here. For some participants it was a sexual attraction that they developed, for others it was something that they were born with.

\section{Categories are limiting boxes}

Categories of lesbianism are ascribed with a set of rules of performance. For example, a butch lesbian is expected to behave in a more masculine manner. This contradicts what her gender performance as a woman 'should' be, and therefore her visibility due to her differences increases. This visibility can have positive effects as well as negative effects. On the one hand the visibility allows butch women to live in an everyday context without having to explain their sexuality through coming out. The following quotes demonstrate how butch lesbians perceived their own visibility:

I think I've been lesbian forever. My mom knew when I was 10 so the setting here and back at home is no different because my teachers back in high school knew that I was a boy. (M).

Visibility also increased their vulnerability as it exposed them to the threat of homophobic violence. Hate crimes are a reality in South Africa and these women were very aware of these dangers, in the university setting, as well as in their home spaces.

Not all your peers are gonna accept the fact that you're gay and a lot of them are gonna come and probably try to change you, you know you're not really like that, half of them become violent towards you, you know? A lot of guys feel that they have the right to own you, to own your body just because you're a female, and you telling them that you're not allowed to have my body as a male person and because I'm not attracted to you makes them violent, you know half of them swear at you, they try to whip your ass, they try to kill you. $(\mathrm{Gu})$.

The term 'fem' had negative and positive aspects. The fact that their sexuality is 'underground' affords them the possibility of 'blending in' with hetero-normative performativity (Scott 1980). This also meant that they were able to choose whether they wanted to be more public or not, either by choosing to be with a partner who is more visible, or by performing more visibly in different spaces. For example, these young women could choose to be 'straight' in the classroom space and 'gay' in queer friendly spaces. Categories were not only those such as 'butch', 'fem', 'futch', and 'lipstick lesbian'; the term lesbian was viewed as a category in and of itself, with its own set of performances attached to this term. The category and its ascription often had negative connotations: 
The hate crimes all that it makes it harder to be like lesbian so I'd rather say I'm straight and date girls I don't know or I'm nothing. Period. (N).

Young lesbian women could see the positive and the negative aspects of labels and opt in or out of using them for different reasons. Their choice of label was directly linked to the setting in which they were located.

A while back I was in a meeting with the Ugandan Human Rights Commission and the woman asked me 'are you a lesbian' and I said 'yes!' without even thinking about it. And it would have never occurred to me to first start saying well I'm actually queer, in that moment where I knew she was very prejudiced against lesbians it was very important for me to say 'yes, I am lesbian'. Strategically it is a good word, sometimes it’s strategic to claim certain identities. (E).

Categories were not only used by the participants, but according to them, the heterosexual contexts made use of the labels in order to understand them better. By using a label that reproduces the gender binary, people are more able to make sense of the performance and the crossing over of the genders, which is what homosexuality is often seen as (Jordanova 1999, 432-444).

\section{The importance of intersectionalities}

\section{Age and sexuality}

I think the beautiful thing for me about the very older lesbians is the way they've kind of settled into who they are. Like they've lived their lives, they've had their struggles and for them it's just 'ah I have a wife, ah I have a girlfriend, I'm gonna go home and cook for them and we're gonna go and celebrate our 50th anniversary ... I no longer need to explain if I'm butch, or futch, or a stud what ever like this is my skin, this is my life, I've lived it, and I'm proud. And that's kind of something I'm a little bit envious of, that settling in a space where its fine. (M).

In terms of intersectionalities with age, there was a perception that a more secure sense of self developed with age, in which an individual was able to explore less comfortable territories and asserting their sexuality was not a priority. Therefore, the idea that older butch lesbians were more comfortable with different sexual practices was expressed by many of the participants.

The sense of stability is not only about sexual practices but also about the performance of sexuality. Several participants perceived older lesbians as being more open to exploring their femininity, even when they had previously been butch.

\section{Career and sexuality}

Career prospects had a significant influence on how participants performed their sexuality. 
Some of the participants had chosen careers which allowed the expression of their identities, while others were faced with the challenge of having to integrate the expectations of their career space and their sexuality in secrecy,

I'm looking at it on a professional [level], I'm thinking it just might be detrimental in terms of like the future like potential career opportunities homosexuality it might just come up if I'm like that radical if I'm in your face kinda thing. (Nt).

The job market has a particular set of rules of behaviour that much like the rest of society reproduces hetero-normativity. Some of the participants chose to be more invisible in their workplace, thus allowing them to blend into the heterosexual world.

\section{Class and sexuality}

Class played a significant role in how relationships were constructed. If class and sexuality are interlinked then the role of power comes to the surface,

A friend of mine dated a worker here at Wits while she was on campus. And it's difficult if someone is earning a grand a month and you're at a university that costs 30 grand a month. (Na).

For this participant, the person in a higher social class had the power to control the other partner, through money. It could also create a situation where the person with less money feels depowered at their inability to contribute equally to the relationship.

\section{Culture and sexuality}

Cultural practices are key determining factors in how identity politics of LGBTI individuals are enacted (Moonsammy 2009, 15-17). There are aspects related to patriarchy within the different cultures in South Africa which oppress women,

I remember the first group of friends I had who weren't all gay, here, consisted of a girl and two dudes and this two dudes were Xhosa, and they'd been to the mountains so they started, before we got to the concept of me being anything other than heterosexual, which they couldn't conceive, they were kind of like 'you're looking me in the eye, you can't do that because you're female and I've been to the mountain' and I was like 'so what?' Because you've been to a mountain, and you've been snapped by whoever, whenever and you didn’t eat for two weeks I suddenly can’t look at you?' (M).

I'm thinking eish and most of them are African so I'm thinking that might all affect my academic progress. (Nt).

These quotes demonstrate how in African cultures the idea that homosexuality is un-African affects the ways in which many people respond to lesbians. The threat of 'corrective' violence was constantly present in the lives of young lesbians. The correction is seen as a form of 
teaching, or putting on track, from the deviation that took place because of exposure to Western culture,

If you compare with other countries, is that we are still very cultural all races and we still are very religious. I'm not charging people in the states or whatever but they aren't as cultural and they're not as religious, because a lot of the stem that homosexuality and gays are wrong is religion based and culture based so South Africa still has that within. (F).

This participant's sentiment demonstrates the link between religion and culture, and the effects these have on the views of homosexuals. Therefore the ability to express ones sexuality is determined by these two very critical factors.

\section{Religion and sexuality}

There were different views regarding the ways in which religion, and specifically religious groups, reacted to homosexuality. Some participants were aware of the discrimination that is perpetrated by religious leaders and members of congregations.

A group of lesbians went to church last month and then the pastor suddenly changed the whole thing, I don't know what the sermon was going to be about but he started talking about homosexuality, when he saw them then the thing change completely and he went into homosexuality condemn you. (Nt).

This quote demonstrates the frustration of some of the participants with the lack of acceptance of religion with regards to their sexualities. On the other hand, some participants felt that religion simply ignored the issue of homosexuality by not discussing it. This was seen as a positive thing by some participants because they also didn't wish to be signaled out as special cases. They felt that sexuality shouldn't be a marker by which they should live all aspects of their lives. This highlights that their identities are in fact intersectional. But on the other hand, there were no gay-friendly religious spaces where those who wished, could be open.

\section{Race and sexuality}

Although homosexual practices form part of many African customs (Potgieter 2003, 271-273), the participants looked to Western culture for identification and spoke about race in relation to Westernisation.

Sexuality and homosexuality and the gay thing is such a Western thing. I think the way us lesbians define ourselves is like through the eyes of Western. This might sound racist but the way we see a white lesbian and that's how we would try, I don't know, play it out. (Nt).

Furthermore, participants were aware of the racial divisions as a legacy of Apartheid and the 
inequalities that persisted. More privileged parts of the LGBTI community had gained access to the rights, whereas the more marginalised (black LGBTI community) remained marginalised. On the other hand, the discourse of the rainbow nation and the apparent equality were continuously used to negate racial differences. One participant shared that, 'white and black have now merged' and thus there is no racial difference.

Race can also represent a barrier to the expression of sexual identity. Race, in as much as it is linked to culture, differentially enables the possibility for these young women to be openly lesbian.

\section{Social markers}

\section{Homophobia as a social marker}

The presence of homophobia formed part of these women's daily cultural encounters in all the different spaces in which these women lived. As a social marker, homophobia determined how much these women concealed about their sexualities. The issue of visibility/invisibility exposed some to more homophobic bullying than others. Some of the participants were confronted with it directly, in some instances receiving 'corrective' remarks from people they had considered friends in the university space. Some participants had experienced the inverse, where close friends accepted their sexuality and turned a blind eye, whilst still maintaining their homophobic views towards other LGBTI people.

\section{Gender performativity}

Gender performativity dictated the ways many of the women behaved in relationships, the roles they adopted (masculine or feminine) and how they were perceived by others.

I think it's more about the role of man and the identity of man so its based on the assumption that every relationship is supposed to have someone who is the man someone who is the woman. And so I may not identify as a man but within our relationship I might say I'm the man. (E).

Maybe they don't coincide with your sexual attraction to women all the time or maybe sometimes one performs things so that its easier or more difficult you know if you're performing super fem then hopefully you wont be attracted to women or something like that, or if you're performing more of a boy then its more acceptable for you to like women. (Na).

While some consciously attempted to break with gender stereotypes, there was still a sense that society would categorise them this way. The appropriation of the term 'queer' was a way of breaking with the gender binaries that allowed these women to express their sexualities in a less constrained manner. In contrast, some participants consciously behaved in gendered ways in 
order to protect their identities as lesbians, especially in spaces where they could be exposed to violence.

\section{Identity and location}

Location was a key influencing factor in the ways these young women expressed their sexual identities. The university could be seen as a queer friendly space that had allowed some to express their sexuality more freely, or begin to think of alternative ways of expressing their sexuality,

It was more the being around people who were interested in the world rather than people who were necessarily interested in lesbian stuff which made me more comfortable to come out. (N).

However some participants expressed that the university was also a site where broader social issues, such as prejudice were still evident. This contrast, together with the presence of LGBTI organisations had allowed many to construct and express their positions and politics around sexuality.

\section{DISCUSSION}

The accounts from participants highlighted the ways in which young lesbian women attending an urban university in South Africa negotiated sexuality. Many of the participants expressed their privileged ability to freely express their sexuality in most contexts, and they acknowledged the difficulties that many other South African lesbian women still face. A critical stance on the current situation for LGBTI people was adopted, the participants were aware of the limitations of the Constitution and its implementation, and the way it selectively privileged LGBTI groups. However, they acknowledged the changes in public perceptions of LGBTI people, the perceived freedoms that the Constitution provided, which, if lost would be detrimental. Comparisons with other African countries afforded these women the ability to stay positive and encouraged these women to fight for social change.

The mixed narratives with regards to the experiences of sexuality in South Africa highlighted that there should be other more appropriate alternatives provided by society for the expression of their sexuality. In line with a queer theory approach, which seeks to contest the presence of binaries related to gender and sexuality, there was acknowledgement from participants that existing categories of lesbian identity could be interpreted in different ways; and secondly, that categories could limit the freedom and fluidity of identity expression. There was a sense that with more freedom of expression, the need for categorisation would fall away. The expression of sexualities that were marginalised in these participants shared many of the 
trends in the negotiation of sexualities by young people across South Africa, for example, the constant negotiation of culture, race, and Western beliefs. There were various markers that affected how young lesbian women created their identities, which were not separate from the hetero-normative rules of society. However, there was an increasing use of queerness as a way of escaping the binaries that dictated how these women behaved, which showed that these women were attempting to contest these categories and adopt more flexible constructions of identity that were context-specific. Old categories of lesbianism are therefore losing their power as identity determinants, and they are being used as ways to classify others but not the self. The university as a setting that has queer-friendly spaces provided the ideal context for the negotiation of different identities, through encounters with others who were alike and different. Thus, in line with queer theory, the data showed that spaces were crucial for contesting existing gender binaries and categories of lesbianism, for the ongoing exploration of different forms of identity expression, and influencing how marginalised identities could be expressed within broader social contexts where inequality and prejudice still persisted.

\section{CONCLUSION}

In conclusion, there are new emerging ways of constructing lesbian identity. This is aided by changes in the social context in terms of policies and shifts between locations within South Africa. The exposure to the university and the differences within provides a relevant space for the development of queer identity. The findings of this research indicated that young lesbian women in contemporary South Africa have a sense of the privileges that changes in social policy have afforded them but they remained critical of the unequal distribution of the benefits. This social consciousness seemed to stem from their exposure to LGBTI organisations, and other LGBTI people, as well as their access to news of homophobic violence. This exposure has also allowed them to develop their sexual identities in ways which were more informed than prior to being in university. This contributed to research on identity negotiation of marginalised groups and more specifically LGBTI in the context of South Africa. This research took a new approach by not focusing on the coming out process as a single stage but rather looking at a continuous negotiation of identity; one which takes into account history, space, and a shift towards the future or intentionality.

\section{Limitations and recommendations}

This research explored the identity expression in young women, attending university, within a metropolitan and cosmopolitan South African university. The political situation of the country 
has created particular markers that make these women's stories specific to the context. Furthermore, this research focused on a particular period in these women's lives and may change with time. Based on the discussion of the results as well as the limitations, it is recommended that this research be extended through utilising different methods and sites of data collection to include the experiences of other young women in other university contexts. Some other methods could include one on one interviews were more in-depth understandings of one person's experience could be gathered.

\section{REFERENCES}

Babbie, Earl and Johann Mouton. 2015. The practice of social research. Cape Town: Oxford.

Balteiro, Isabel. 2015. Social changes reflected in specialized languages: Lexical re-/deconstruction in lesbian studies. Procedia - Social and Behavioral Sciences 173(2015): 307-311.

Braun, Virginia and Victoria Clarke. 2006. Using thematic analysis in psychology. Qualitative Research in Psychology 3(2): 77-101.

Butler, Judith. 1999. Gender trouble: Feminism and the subversion of identity. New York: Routledge.

Davis, Kathy. 2008. Intersectionality as buzzword: A sociology of science perspective on what makes a feminist theory successful. Feminist Theory 9(1): 67-85.

Davis, Rebecca. 2012. SA’s gay hate crimes: An epidemic of violence less recognized. Daily Maverick, 27 June 2012.

Eves, Alison. 2004. Queer theory, butch/femme identities and lesbian space. Sexualities 7(4): 480-496.

Geerts, Evelien and I. van der Tuin. 2013. From intersectionality to interference: Feminist ontoepistemological reflections on the politics of representation. Women's Studies International Forum 41(3): 171-178.

Gontek, Ines. 2009. Sexual violence against lesbian women in South Africa. Outliers, a Collection of Essays and Creative Writing on Sexuality in Africa 2: 1-18.

Griffith, Kirsten and Michelle R. Hebl. 2002. The disclosure dilemma for gay men and lesbians: 'Coming out' at work. Journal of Applied Psychology 87: 1191-1199.

Harris, Bronwyn. 2004. Arranging prejudice: Exploring hate crime in post-apartheid South Africa. Race and citizenship in transition series. Braamfontein: Centre for the Study of Violence and Reconciliation.

Harris, Laura A. 2002. Femme/butch family romances: A queer dyke spin on compulsory heterosexuality. Journal of Lesbian Studies 6(2): 73-84.

Hill Collins, Patricia. 1998. It's all in the family: Intersections of gender, race, and nation. Hypatia 13(3): 62-82.

Jagose, Annemarie. 1996. Queer Theory: An Introduction. New York: New York University Press.

Jordanova, Ludmilla. 1999. Natural facts: A historical perspective on science and sexuality. In Feminist theory and the body - A Reader, ed. Janet Price and Margrit Shildrick, 432-444. New York: Routledge.

Kotze, Ella, S. G. 2010. Lesbians' coming-out stories as confessional practices: Liberatory politics or an incitement to discourse? Unpublished Masters Research Report. University of the Witwatersrand.

Kulick, Don. 2000. Gay and lesbian language. Annual Review of Anthropology 29: 243-285.

Lewis, Jane. 2003. Design issues. In Qualitative research practice: A guide for social science students and researchers, ed. Jane Lewis and Jane Ritchie, 56-76. London: Sage. 
Moonsammy, Davina. 2009. What will people say? Three stories of Indian women loving women in Jozi. Unpublished Doctoral Thesis. University of the Witwatersrand.

Mooney, Gillian and Peace Kiguwa. 2009. Gender identity: Contestations and questions. In Developmental psychology, ed. Jacqueline Watts, Kate Cockcroft and Norman Duncan, 600-616. Landsdowne: UCT Press.

Nel, Juan, A. and Melanie Judge. 2008. Exploring homophobic victimisation in Gauteng, South Africa: Issues, impacts and responses. Acta Criminologia 21(3): 19-36.

Nkabinde, Nkunzi Z. 2008. Black bull, ancestors and me: My life as a lesbian sangoma. Sunnyside: Jacana Media.

Oswin, Natalie. 2008. Critical geographies and the uses of sexuality: Deconstructing queer space. Progress in Human Geography 32(1): 89-103.

Pakade, Nomancotsho. 2013. Exploring Meanings Attached to the Sexual Identity of Black-Women Loving-Women in Soweto. Unpublished Masters Research Report, University of the Witwatersrand.

Potgieter, Cheryl. 2003. Lesbianism. In Social psychology: Identities and relationships, ed. Kopano Ratele and Norman Duncan, 269-288. Lansdowne: UCT Press.

Roberts, Benjamin, Ari Sitas and Ran Greenstein. 2003. Qualitative research methods. In Research methods manual, ed. Ran Greenstein, 1-103. Unpublished.

Scott, Joan W. 1980. Gender and the politics of history. New York: Columbia University Press.

Smorag, Pascale. 2008. From closet talk to PC terminology: Gay speech and the politics of visibility. Transatlantica: Revue d'Études Américaines Smorag 1. http://transatlantica.revues.org/3503 (accessed 28 August 2015).

Stanley, Julia. 1970. Homosexual slang. American Speech 45(1/2): 45-59.

Thomas, Kylie. 2013. Homophobia, injustice and 'corrective rape' in post-apartheid South Africa. Braamfontein/Belville: Centre for the Study of Violence and Reconciliation and Centre for Humanities Research, University of the Western Cape.

Walker, Ja'nina J., Sarit A. Golub, David S. Bimbi and Jeffrey T. Parsons. 2012. Butch bottom-femme top? An exploration of lesbian stereotypes. Journal of Lesbian Studies 16(1): 90-107. 